\title{
ESCAVANDO EM CASA
}

Layla Chaves Lucena ${ }^{1}$

\section{RESUMO}

O artigo Escavando em Casa deriva de uma pesquisa desenvolvida com o objetivo de compreender aspectos do cotidiano de um grupo doméstico ${ }^{2}$ que em algum momento utilizou, ou ainda utiliza, o sítio arqueológico denominado "Sítio Branco". O trabalho objetiva compreender uma história que não está escrita em documentos oficiais, mas que pode ser resgatada valendo-se de outras fontes como, neste caso, a cultura material. Além de responder a algumas perguntas previamente elaboradas, 0 desenvolvimento da pesquisa permitirá ao leitor compreender os métodos e técnicas da arqueologia, que, se devidamente aplicados, podem levar ao entendimento de um grupo de pessoas, e até mesmo da sociedade.

Palavras-chave: Arqueologia; Técnicas; Métodos; Cotidiano; Documentação Material

\section{ABSTRACT}

This article Excavating Home derives from a survey conducted in order to understand everyday aspects of a domestic group at some time used, or use, the archaeological site called "White site". The study aims to understand a story that is not written in official documents, but that can be redeemed drawing on other sources such as, in this case, the material culture. In addition to answering some previously prepared questions, the development of the research will allow the reader to understand the methods and techniques of archeology, which, if properly applied, can lead to the understanding of a group of people, and even the society.

Keywords: Archaeology; techniques; methods; daily; material documentation

\section{RESUMEN}

\footnotetext{
${ }^{1}$ Licenciatura em História e Especialização em Arqueologia, História e Sociedade - Universidade de Santo Amaro.

2 O conceito de grupo doméstico refere-se a um grupo de pessoas, independente do grau de parentesco, coexistindo em uma residência e, que até certo ponto, compartilha de suas atividades de manutenção e das decisões a ela relacionadas (BLANTON, 1994, p. 05 apud SYMANSKI, 2008 p. 7).
}

\begin{tabular}{|l|l|l|l|l|l|l|}
\hline (C) Rev. Arqueologia Pública & Campinas, SP & v. 10 & n. 1 & p. 51-60 & MAR. 2016 & ISSN 2237-8294 \\
\hline
\end{tabular}




\section{Revista de Arqueologia Pública}

Ese artículo Excavando en Casa deriva de una encuesta realizada a fin de comprender los aspectos cotidianos de un grupo doméstico usado en algún momento, o el uso, el sitio arqueológico llamado "sitio blanco". El estudio tiene como objetivo comprender una historia que no está escrita en los documentos oficiales, pero que puede ser redimida de traer de otras fuentes, tales como, en este caso, la cultura material. Además de responder a algunas preguntas preparadas previamente, el desarrollo de la investigación permitirá al lector comprender los métodos y técnicas de la arqueología, que, si se aplican correctamente, pueden conducir a la comprensión de un grupo de personas, e incluso la sociedad.

Palabras clave: Arqueología; técnicas; métodos; cotidiano; documentación de los materiales

\section{INTRODUÇÃO}

A intervenção arqueológica aqui apresentada foi empreendida com o intuito de compreender aspectos do cotidiano de um grupo doméstico utilizando primordialmente a documentação material como fonte histórica.

Além disso, o desenvolvimento da pesquisa demonstrará o importante papel da cultura material no entendimento e análise de um grupo de pessoas. Os artefatos carregam involuntariamente ideias e hábitos de uma época, de maneira que o estudo destes objetos permite conhecer em essência a sociedade que o produziu.

Isto se torna possível pois os artefatos são produto do trabalho humano e, portanto, apresentam duas facetas: possuem funções primárias (sua utilidade prática) e funções secundárias (simbólicas). O artefato é, portanto, direcionador e mediador das atividades humanas (FUNARI, 2003, p. 33).

Certo é que a cultura material vem demonstrando há muito o seu poder documental, no entanto o que poderemos comprovar com esta pesquisa é que, para que se consiga alcançar os objetivos propostos, é indispensável que o profissional siga corretamente os métodos da arqueologia.

A arqueologia é uma ciência composta de teoria e métodos que não permite ao estudioso se desprender de certas técnicas uma vez que, alterado, o sítio arqueológico é destruído, não sendo permitido um novo estudo.

Para atingir os objetivos citados, foi aplicado no sítio Branco o método de escavação estratigráfica ${ }^{3}$. Por meio da análise do material coletado, da composição do material, e da disposição dos mesmos no contexto de achado, algumas hipóteses puderam ser levantadas acerca dos seguintes questionamentos:

1. Qual o padrão de organização utilizado por este grupo doméstico?

2. O que o material consegue orientar sobre as pessoas que ocuparam ou ocupam este local?

\footnotetext{
3 "Podem-se dividir os procedimentos de escavação arqueológica, segundo seus objetivos gerais, em dois amplos campos: (1) o desenterramento, que visa apenas à recuperação de estruturas arquitetônicas e de artefatos, sem se preocupar com a situação espacial do sítio arqueológico e (2) a escavação estratigráfica, voltada para uma reconstrução da história detalhada do sítio arqueológico escavado" (FUNARI, 2003, p. 64).
}

\begin{tabular}{|l|l|l|l|l|l|l|}
\hline (C) Rev. Arqueologia Pública & Campinas, SP & v. 10 & n. 1 & p. 51-60 & MAR. 2016 & ISSN 2237-8294 \\
\hline
\end{tabular}




\section{ARTIGO}

\section{Revista de Arqueologia Pública}

3. O que a análise do material consegue orientar sobre o modo de vida da sociedade da época?

Neste trabalho, as técnicas e métodos da arqueologia foram aplicados em um ambiente totalmente inusitado: o armário de louças de uma casa (nomeado "Sítio Branco").

A arqueologia não está presa nem ao tempo, nem ao espaço, seu campo de estudo é a cultura material de qualquer época, passada ou presente (FUNARI, 2003, p. 13), e seu objeto de estudo são os grupos humanos, conforme destaca a citação, extraída da Carta de Lausanne ${ }^{4}$ :

O Patrimônio arqueológico engloba todos os vestígios da existência humana e interessa a todos os lugares onde há indícios de atividades humanas, não importando quais sejam elas; estruturas e vestígios abandonados de todo tipo, na superfície, no subsolo ou sob as águas, assim como o material a eles associados (Carta de Lausanne in SOUZA; BASTOS, 2010, p. 110).

O material encontrado foi bastante revelador, tendo em vista que se trata de um conjunto de artefatos de uso cotidiano, o que pode fornecer informações mais completas sobre as pessoas que utilizaram este sítio. A área escavada foi delimitada por ser o local onde se verificou maior quantidade de material cerâmico.

\footnotetext{
${ }^{4}$ Carta para proteção e Gestão do Patrimônio Arqueológico. A carta de Lausanne propõe-se a enunciar os princípios fundamentais e recomendações de alcance global no que se refere à conservação dos monumentos e sítios arqueológicos (SOUZA; BASTOS, 2010, p. 109).
}

\begin{tabular}{|l|l|l|l|l|l|l|}
\hline (C) Rev. Arqueologia Pública & Campinas, SP & v. 10 & n. 1 & p. 51-60 & MAR. 2016 & ISSN 2237-8294
\end{tabular}




\section{ARTIGO}

\section{Revista de Arqueologia Pública}

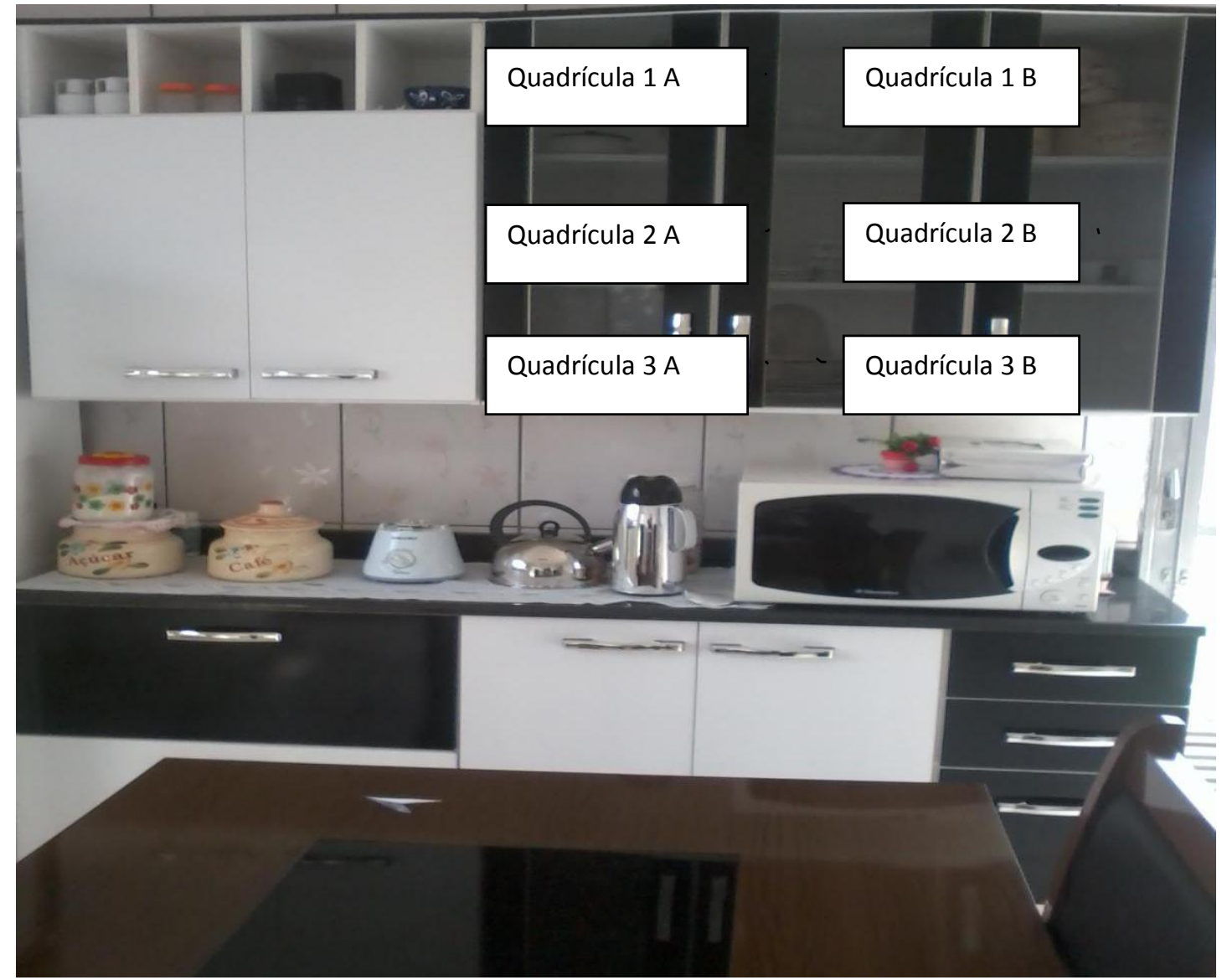

Figura1 - Sítio Branco

\section{FASES DO TRABALHO ARQUEOLÓGICO EMPREENDIDO}

1. Sondagem;

2. Escavação;

3. Análise do material / Laboratório;

4. Divulgação da pesquisa / Educação Patrimonial;

Para o desenvolvimento de qualquer trabalho arqueológico, as etapas citadas acima são fundamentais. Portanto no trabalho desenvolvido no Sítio Branco, estas etapas foram reproduzidas.

\section{SONDAGEM}

Nesta pesquisa, o material escolhido para ser analisado foram as louças que, por serem objetos de uso cotidiano, foram aqui consideradas como o material com maior potencial para responder 


\section{Revista de Arqueologia Pública}

aos questionamentos iniciais. Para a delimitação da área escavada, foram realizadas sondagens ${ }^{5} \mathrm{com}$ o intuito de identificar onde haveria maior incidência deste material.

As quadrículas foram abertas nos locais onde se verificou, durante o processo de sondagem, maior quantidade de material cerâmico. As quadrículas são o resultado da divisão de uma área a ser escavada em quadrados, como se aplicássemos um papel quadriculado a uma superfície (FUNARI, 2003, p. 74).

Durante o processo de escavação, caso fossem encontrados outros tipos de material, os mesmos deveriam ser devidamente documentados e guardados para estudos posteriores.

\section{ESCAVAÇÃO}

O Sítio Branco possui 2,90m de altura por $3 \mathrm{~m}$ de largura. Tendo em vista os objetivos da pesquisa, as quadrículas foram abertas ao sul do sítio, pois foi nesta direção que se verificou a existência do material escolhido para análise.

\section{COLETA DE MATERIAL E ANÁLISE}

Quadrícula 1A - 69cm de largura / $29,5 \mathrm{~cm}$ de altura.

Foram evidenciados três objetos:

- 2 travessas de vidro transparente.

As travessas estavam organizadas por tamanho, uma delas de forma retangular e a outra redonda, ambas confeccionadas em vidro bastante espesso, com $0,05 \mathrm{~cm}$ de espessura. As duas travessas apresentam marcas de queima, o que nos leva a crer que este tipo de vidro pode ser levado ao fogo.

- 1 vasilha pequena, branca, em cerâmica com tampa em madeira. Esta vasilha apresenta uma grande rachadura em sua parte interna.

Quadrícula 2A - 69cm de largura / 28,5cm de altura.

Foram evidenciados trinta objetos:

- 2 travessas brancas, quadradas, de mesmo tamanho com inscrição (Porcelana Pozzani) e logomarca (Concert) nas cores verde e preto;

- 3 travessas brancas, redondas, de mesmo tamanho com inscrição (Porcelana Pozzani) e logomarca (Concert) nas cores verde e preto;

5"As sondagens são escavações menores que permitem saber a profundidade do sítio e, em caso de sucessivos pavimentos sobrepostos, escolher aquele que, por sua densidade ou pelo interesse na atualidade, deve ser atingido pelo desenterramento" (FUNARI, 2003, p. 66).

\begin{tabular}{|l|l|l|l|l|l|l|}
\hline (C) Rev. Arqueologia Pública & Campinas, SP & v. 10 & n. 1 & p. 51-60 & MAR. 2016 & ISSN 2237-8294 \\
\hline
\end{tabular}




\section{Revista de Arqueologia Pública}

- 3 xícaras brancas, pequenas com inscrição (Porcelana Pozzani) e logomarca (Concert) nas cores verde e preto;

- 3 xícaras brancas com alça fumê, em acrílico, com inscrição (Clio Style);

- 6 pires em acrílico fumê;

- 2 pires brancos com decoração rosa em cerâmica;

- 4 pires brancos com detalhes em laranja e roxo em cerâmica;

- 6 pires brancos com detalhes em verde e preto, com inscrição (Porcelana Pozzani);

- 1 pires branco com inscrições (Café Bistrô MilkShakespeare, e Porcelana Schmidt - Made in Brazil).

Quadrícula 3A - $69 \mathrm{~cm}$ de largura / $28,5 \mathrm{~cm}$ de altura.

Nesta quadrícula, somente pratos foram encontrados, num total de 26 objetos.

- 3 pratos médios de vidro transparente;

- 12 pratos com mesma decoração e cor (brancos com pintura rosada), de tamanhos e formas diferenciadas (4 pratos rasos médios, 4 pratos fundos médios e 4 pratos rasos pequenos), em cerâmica;

- 1 prato médio, branco, com inscrição (Porcelana Pozzani) e logomarca (Concert) nas cores verde e preto;

- 6 pratos grandes, brancos com mesmo tamanho e a mesma decoração na borda (metálica), com inscrição (Porcelana Ganzarolli);

- 2 pratos brancos e grandes, com mesmo tamanho e decoração floral, com tons avermelhados, amarelo e verde, em cerâmica;

- 1 prato branco médio, sem decoração, em cerâmica;

- 1 prato grande branco, com motivos florais nas cores azul, amarelo, verde e tons rosados, com inscrição (Fabricado na China), em cerâmica.

Quadrícula 1B - $34,5 \mathrm{~cm}$ de largura / $29,5 \mathrm{~cm}$ de altura.

Foram evidenciados três potes em cerâmica, na mesma cor, tamanho e modelo.

Quadrícula 2B - $34,5 \mathrm{~cm}$ de largura / $28,5 \mathrm{~cm}$ de altura.

Foram evidenciados seis objetos:

- 1 prato pequeno confeccionado em madeira;

- 1 taça de vidro transparente, com alça;

- 1 copo de plástico grande;

- 1 copo médio de alumínio;

- 2 pires brancos com decoração rosada em cerâmica.

Quadrícula 3B - $34,5 \mathrm{~cm}$ de largura / $28,5 \mathrm{~cm}$ de altura 


\section{Revista de Arqueologia Pública}

Foram evidenciados doze objetos:

- 3 xícaras brancas com detalhes em rosa em cerâmica. Uma das xícaras apresenta a alça quebrada;

- 1 xícara branca com decoração em roxo, verde e amarelo, em cerâmica, e que apresenta uma rachadura;

- 4 copos grandes em vidro transparente;

- 1 xícara grande com alça, de cor marrom no exterior e bege no interior, confeccionada em cerâmica;

- 1 cinzeiro branco com decoração verde e preto com duas inscrições (Porcelana Pozzani, e Rua Barão de Jundiaí, 314 - Jundiaí - São Paulo);

- 2 pires brancos com decoração em vermelho e roxo, em cerâmica.

Uma análise prévia do material encontrado permitiu que fossem feitas as seguintes considerações:

1. A organização das louças neste sítio foi feita essencialmente por tamanho, com os objetos colocados uns sobre os outros. Somente na quadrícula 3A foi encontrado um mesmo tipo de objetos (pratos); nas demais quadrículas, vários tipos de objetos foram encontrados, o que demonstra que a organização escolhida não obedece a critérios de separação por função ou forma.

2. Há preferência por louça na cor branca. Algumas peças em cerâmica chegam a parecer bastante com a porcelana, um material mais caro, mas a diferença pode ser percebida após um olhar bastante atento, pois a porcelana difere-se da cerâmica por sua vitrificação, resistência, completa isenção de porosidade e sonoridade ${ }^{6}$.

3. Não existe muita preocupação com o descarte definitivo, pois algumas peças foram encontradas com rachaduras.

4. Várias peças apresentam a logomarca Concert.

Foi possível identificar que não existe grande preocupação com o descarte, pois várias peças apresentam partes lascadas, ou rachaduras. A análise laboratorial também permitiu averiguar que, enquanto a peça esteve apta para uso, foi mantida. Isto nos remete ao pensamento de que elas podem pertencer a um grupo com nível socioeconômico não muito elevado, e isto se pode supor também pela ausência de grandes jogos de louça e peças mais refinadas.

Foram encontradas neste sítio 90 peças, mas chama atenção o número desproporcional de pratos (26) e copos (6). Uma possibilidade, é que os copos, por serem fabricados em material mais frágil, não tenham resistido em maior número.

\footnotetext{
${ }^{6}$ Disponível em http://www.porcelanamizuno.com.br/curiosidades.htm, acessado em 02 de junho de 2012.
} 


\section{ARTIGO}

\section{Revista de Arqueologia Pública}

O cinzeiro encontrado na quadrícula 3B forneceu uma valiosa informação a respeito da inscrição CONCERT, encontrada em algumas peças. Este nome apresenta um desenho, tratando-se, portanto de uma logomarca. Em pesquisa realizada na cidade de Jundiaí, soube-se que na região central desta cidade, funcionou há 6 anos um restaurante de nome Concert Tayo.

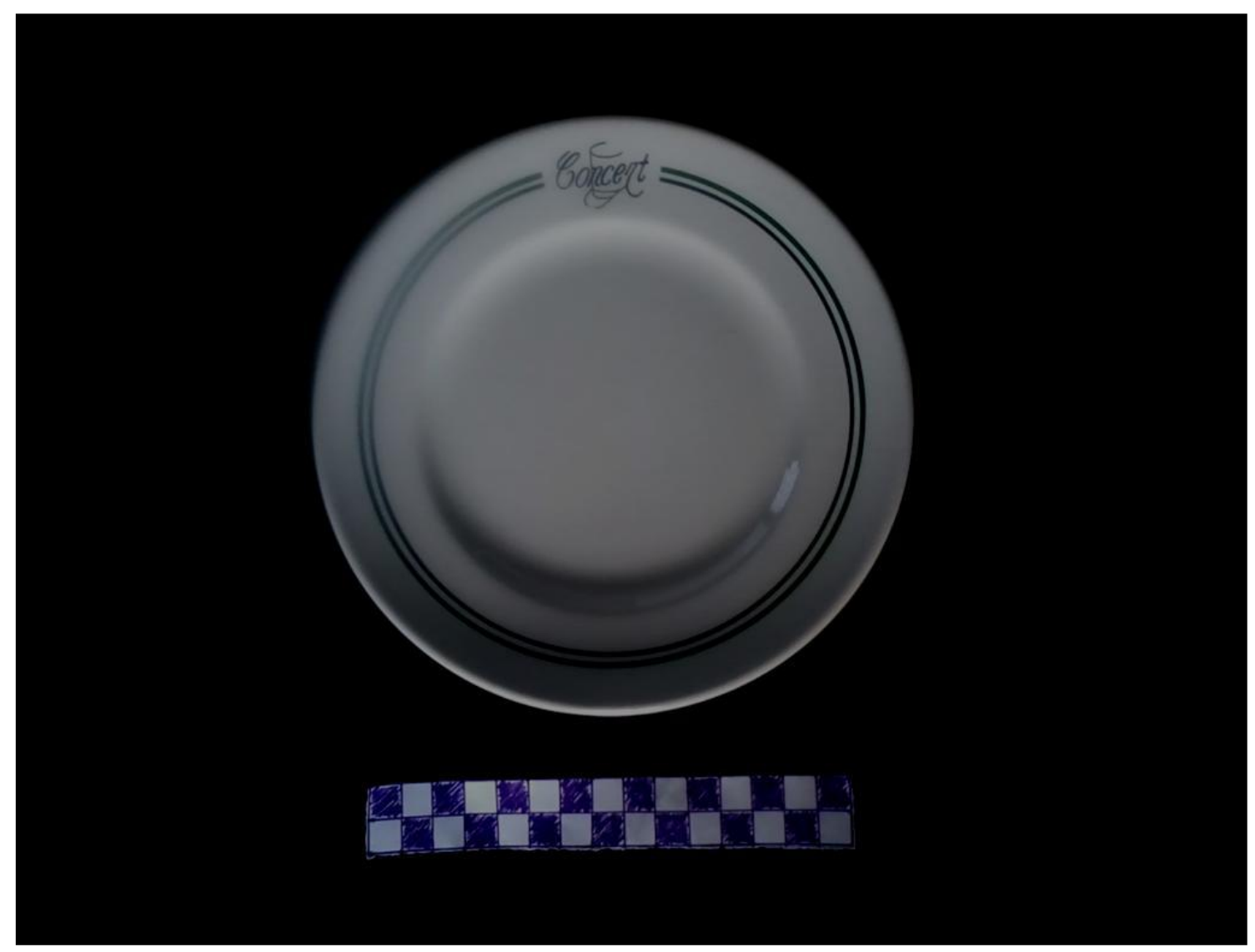

Figura 2 - Pires em porcelana com a logomarca Concert

A análise destes artefatos permitiu verificar que a utilização do Sítio Branco se deu em um momento em que uma camada menos abastada da sociedade passou a ter acesso a louças mais elaboradas, já que apresentou algumas peças em porcelana, e louças mais decoradas.

Mas as peças estavam apenas guardadas e não expostas como um bem valioso, e possivelmente eram utilizadas no cotidiano deste grupo doméstico, não sendo preservadas para uma possível exposição aos convidados.

\section{CONSTATAÇÕES}

A análise do material encontrado permitiu que algumas constatações fossem feitas:

- O padrão de organização utilizado neste sítio é essencialmente o de sobreposição de peças (uma sobre a outra), que também é uma forma de ganhar espaço; 


\section{Revista de Arqueologia Pública}

- Há a predileção por louças na cor branca, mas estas louças foram confeccionadas em diferentes materiais. Pode-se perceber também que a maioria destes objetos era regularmente utilizada, pois grande parte deles apresenta marcas de desgaste;

- As peças eram mantidas enquanto pudessem exercer sua função. Algumas peças apresentam rachaduras mas, por ainda estarem aptas para uso, não foram definitivamente descartadas;

- Algumas peças possuem logomarca, o que permite inferir que foram confeccionadas para uso comercial (peças com a inscrição Concert, e pires Café Bistrô MilkShakespeare), mas que por algum outro motivo, foram trazidas para uso doméstico.

\section{DIVULGAÇÃO DA PESQUISA}

A divulgação da pesquisa pode ser considerada a etapa mais importante do trabalho arqueológico. Arqueólogos de todo o mundo têm o dever de publicar suas pesquisas, trazendo a público as informações e dados levantados com as escavações, a fim de efetivamente transformar o trabalho em conhecimento.

No Brasil, especialmente, este é um desafio ainda maior pois, aqui, a arqueologia não é tão divulgada e conhecida como em outros países, apesar de estar relacionada à criação e a valorização da identidade nacional ou cultural (FUNARI, 2003, p. 101).

No entanto, é trabalho de todo arqueólogo e estudante de arqueologia demonstrar todo o potencial desta ciência na análise e compreensão de seu objeto de estudo: as sociedades humanas. É necessário elucidar o que a arqueologia realmente é, resgatando-a da fantasia e a trazendo para a realidade.

Visando atingir esse objetivo, e inserir a arqueologia no imaginário das pessoas da maneira como ela realmente é - uma ciência -, o trabalho Escavando em Casa está sendo cotado para fazer parte de uma oficina de arqueologia, em uma escola Estadual da cidade de Várzea Paulista.

É importante que jovens do ensino fundamental e médio tomem conhecimento dos fundamentos da arqueologia e se apropriem dos conhecimentos por ela adquiridos, a fim de auxiliar no processo de formação de suas identidades. Reconhecer que todos os povos produzem cultura é entender o nosso modo de ser no mundo (SOUZA; BASTOS, 2010, p. 218).

A arqueologia, assim como outras ciências, não pode ser elitizada. Ela está a serviço da sociedade e, para que de fato isto aconteça, o cidadão precisa saber que ela existe, como e onde atua.

\section{REFERÊNCIAS BIBLIOGRÁFICAS}

BLANTON, R. Houses and Households: A Comparative Study. New York, Plenum Press. 1994 in SYMANSKI, Luís Claudio P. Práticas econômicas e sociais no sertão cearense no século XIX: 


\section{ARTIGO}

\section{Revista de Arqueologia Pública}

um olhar sobre a cultura material de grupos domésticos sertanejos. Revista de Arqueologia, 21,

n.2: 73-96, 2008.

FUNARI, Pedro Paulo Abreu. Arqueologia. Editora Contexto. 2003

SOUZA, Marise Campos e BASTOS, Rossano. Normas e Gerenciamento do Patrimônio Arqueológico.

Superintendência do IPHAN em São Paulo. 2010

Site consultado:

http://www.porcelanamizuno.com.br/curiosidades.htm - Acesso em 02 de junho de 2012.

\section{AGRADECIMENTOS}

Agradeço, sinceramente, a Deus, e a todos aqueles que tornaram esta pesquisa muitíssimo agradável: meus pais, amigos com quem compartilhei esta experiência, e aos professores Vagner Carvalheiro Porto e Carolina Kesser Barcellos Dias. 